\title{
Designing a Postcode System for Arbil City Iraq
}

\author{
Sara Muhamad Amin and David Wilson
}

\begin{abstract}
Today, as a result of developing and expanding cities, postal systems need to be devised to include a more robust sense of adaption and expansion for the growing city. An issue surrounding most current postcode systems such as the American Zip code and the UK postcode is the lack of direction and distance from a given point such as a city or urban centre. The aim of this study is to design a postcode system based on a sense of direction and distance from the central of an area. This paper presents a new method of postcode design that provides a sense direction by using a diagonal division with area classification numbers according to the main directions (North, South, East and West). As such, a postal region is divided into several zones by using the outward section of the proposed postcode to form a sense of distance from a central point. This proposed arrangement will be beneficial for developing countries that have the desire to start designing their own postcode system and will facilitate the improvement of postal delivery for developed countries.
\end{abstract}

Index Terms-Postcode, postal code, zip code, mailing system.

\section{INTRODUCTION}

It is becoming increasingly difficult to ignore the utilization of postcodes in developed countries. Recent developments in expanding areas, increasing communication and traveling have heightened the need for navigation systems that are based on postcodes. The postcode is a set of numbers or numbers and letters joined together in some specific form to show the approximate location of an address. This system is referred to as postcode in the UK and ZIP code (Zone Improvement Plan) in the USA, in other countries such as Austria, Belgium, Canada, and Denmark it is known as a Postal Code. The postcode takes various forms in different countries. If the system is alphanumeric then both letters and numbers are used whereas the American ZIP code format uses only numbers.

One major theoretical issue that has prevailed in the postal field for many years relates to a lack of research and sources of information about postcode systems. Also, far too little attention has been paid to designing a standard postcode system for developing countries that may desire to introduce their own system. One question that is being investigated is whether a postcode can be designed based on area layout. This paper suggests a standard method for a postal system based on a sense of direction and distance.

\section{A. Problem Statement}

There is an absence of good quality research into postal

Manuscript received February 12, 2014; revised April 17, 2014.

The authors are with the University of Huddersfield, School of Computing and Engineering, Huddersfield, UK (e-mail: Sara.Muhamadamin@hud.ac.uk,d.r.wilson@hud.ac.uk). systems.

The design of postcode systems is limited.

\section{B. Research Hypotheses}

Can a postcodes system provide a sense of direction and distance from a defined set point?

\section{Research Objective}

To establish a postcode system based on direction and distance from the specific point with limited number of alpha-numeric characters.

\section{Postcode}

A postcode (known in various countries as a postal code, post code, or ZIP code) is a set of digits and/or letters added to a postal address to aid in the sorting of mail. Once postcodes were introduced, several electronic applications became possible [1]-[3].

According to the last survey by the Universal Postal Union (UPU) in 2012, 142 of the 192 member countries of the UPU have a postcode system, and 55 different kinds of electronic services are offered by post. Postcodes are usually linked to geographical areas. Special codes may be assigning to individual addresses or to institutions that receive large volumes of mail, such as large commercial companies and Governmental public service directorates. One example is the French CEDEX system [3].

The importance of having a correctly identified location makes the sorting and delivering of mail easy and quick. The, postcode provides those involved in mail exchanges, a sense of satisfaction and confidence in the mail medium and in a country's postal administration. Having a well-organized postcode system decreases the delivery cost of mail and parcels for the mailer as well as for the addressee [3].

In the United States, the Zone Improvement Plan (ZIP code) system was rolled out consisting of five digits. The first digit symbolizes a certain group of USA states; which divides the USA into 10 large groups of states numbered from 0 in the Northeast to 9 in the West. Within these large areas, smaller geographic areas were created and identified by the 2 nd and 3 rd digits of the ZIP code. Finally the 4th and 5th digits identify a post office or local delivery area [4], [5].

To make the ZIP code system representation more specific, 4 extra digits were added to the ZIP code system in 1983 by the US postal service (USPS) and the new system was known as "ZIP+4", often called "plus-four codes" or "add-on codes" [5]. The additional four digits are used by the USPS automated equipment for mail sorting according to the specific mail carrier (postman). A delivery 'sector', such as city blocks, a group of streets, office buildings, or a small geographical area is represented by the first two digits of the 
additional four digits. The last two digits represents the specific segment, such as a floor of an office building, one side of a street, a firm, a city council office block or other specific geographical place [4], [6].

An Australian postcode was introduced in 1967. The design is based on 4-digit numeric codes. The first digit indicates the state or territory and the last three digits indicate a delivery area. To indicate a specific location such as a single building or house, the street name and location number are used. There are some exceptions to these rules, where state borders are geographically confusing or a postcode spans more than one state. The Australian postcode is similar to the first segment of the ZIP code of the United States where both systems are designed based on numerical codes. The now dissimilarity between them comes as a result of improving the ZIP code system of USA to ZIP+4 system, which defines the specific location by 9 digits [1], [7].

The postcode system of Canada consists of six alphanumeric characters in the form of "ANA NAN" where "A" represents the alpha character and " $N$ " represents a numeric character. The outward segment is known as the Forward Sortation Area (FSA) and the inward section is known as the Local Delivery Unit (LDU) as shown in Fig. 1. The FSA is a combination of (Alpha-Numeric-Alpha). It represents a major geographic location of urban or rural places. The LDU is a combination of (Numeric-Alpha-Numeric). It represents the smallest delivery unit within a specific FSA [7].

\section{M4B 1 G5

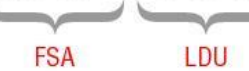

Fig. 1. postcode structure of Canada [7].

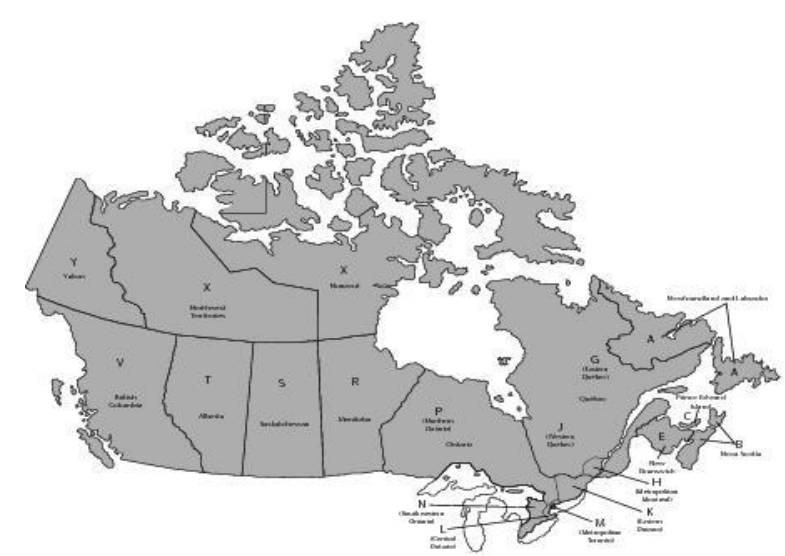

Fig. 2. First segment of postcode of Canada (FSA) [7].

A specific area within a major geographic region or province is defined by the first segment of the postcode (FSA). This segment is used as base for the primary sorting of forward mail. The first character of FSA identifies one of the 18 major geographic areas, provinces or districts of Canada as shown in Fig. 2.

The second character of FSA identifies an urban or a rural location within the geographic area. Numbers from 1 to 9 identify urban Locations (ex. M2T) and 0 identifies a rural location (ex. A0A). The third character of FSA in conjunction with the first two characters, defines an exact area in a city or town or other geographic area as shown in Fig. 3.

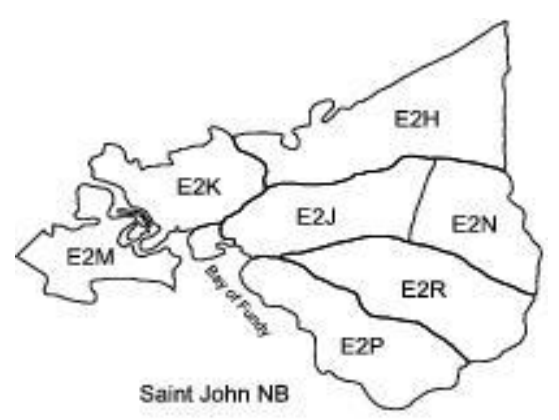

Fig. 3. Example FSA of Canada [7].

The three characters of the second segment (LDU) within an urban areas indicates a specific city block (one side of a street between two intersecting street), a single building or, in some cases, a large volume mail receiver. In rural areas, LDU, together with FSA, identify a specific rural community [1], [7].

In Andorra, a postcode system was introduced in July 2004 approximately 11 years after becoming a sovereign nation in May 1993. The format [AD] NNN was chosen. AD represents the country code and the first number can be in the range 1-7 to represent the 7 parishes of Andorra. The last two numbers are usually 00 and the specific location can be addressed using a street name and the house or building number. 01 is used for the last two digits for post offices. For example, a letter sent to a PO Box address in Andorra la Vella parish would require the postcode AD501.

The similarity between the Canadian and Andorran postcodes is presented by dividing the countries into distinct geographic sectors, although letters are used in Canada and by numbers in Andorra. Unlike the Canadian postcode, the postcode of Andorra is simple and does not indicate any specific point, other than the address of post offices [8], [9].

In 1959, a six-character postcode system was attempted in Norwich in the east of England. The letters NOR were meant to represent the city with a further three characters to represent a street. The current United Kingdom postcode system was rolled out across the UK, including the re-numbering of Norwich in 1974. The UK postcode consists of two sections separated by a space. It is an alphanumeric system that combines letters and number using six different formats. The UK postcode format is more geographically detailed than other countries. The symbol of a major city or town can be seen at the beginning of the first part of the code, and the district number at the end of the first section. In the second part of the postcode, a specific geographic location can be seen [2].

Similar to the Canadian, Andorran and other well-known $\mathrm{ZIP} /$ postcodes, the UK postcode has not been designed to indicate direction and distance from a specific point. However, an indication of direction can be seen in postcodes of some cities. For example, London is divided into 8 districts North (N), North West (NW), West (W), West Central (WC), South West (SW), South East (SE), East (E) and East Central (EC) [2]. The proposed method, currently under investigation, is similar in nature to the $\mathrm{UK}$ and Canadian postcode in that it 
will consist of two sections of alphanumeric code. However, unlike the UK and Canadian postcodes, the proposed system provides a code for geographic locations based on the direction and the distance of the geographic location from the center of a city or town as illustrated in Section III.

\section{Postcode DESIGN}

\section{A. A new Method for Postcode Design}

We assert that the alphanumeric system can give more code integration by fewer characters if compared with the numeric system such as that of the ZIP code, which in its current format contains up to 9 numeric characters. The postcode system for a city or town can be designed by 5 to 7 alphanumeric characters. Therefore, the preferred format for the design of this postcode system is an alphanumeric code. The chosen postcode formats are assigned thus, where $\mathrm{L}$ symbolizes a Letter and $\mathrm{N}$ a Number:

$\begin{array}{ll}\text { LN } & \text { NLL } \\ \text { LNN } & \text { NLL } \\ \text { LNL } & \text { NLL } \\ \text { LLN } & \text { NLL } \\ \text { LLNN } & \text { NLL } \\ \text { LLNL } & \text { NLL }\end{array}$

The chosen postcode formats consist of two parts separated by a space. The first part of postcode known as the outward section represents the city character and distance zone from the central point, while the second part, known as the inward section represents the direction and a specific street. The first character of inward section is the direction and the last two characters specify the point.

Only 20 characters will used as some letters and numbers can be mistaken for other characters. For example, 0 and $\mathrm{O}, 1$ and I, U and V. As a result twenty characters from the Roman alphabet are used in the postcode system which are A, B, C, D, E, F, H, J, L, N, P, Q, R, S, T, U, W, X, Y and Z.

The proposed method in this research is flexible and adaptable with different city styles to gives the sense of directions and the distance from the centre of the city. The design can be done according to the following steps:

\section{1) Step one}

Divide the city using two divisional diagonals passing through the centre of the city thereby dividing the city in to four parts (North, East, South and West) as shown in Fig. 4. The diagonals can be selected according to available main streets or roads depending on the urban geography.

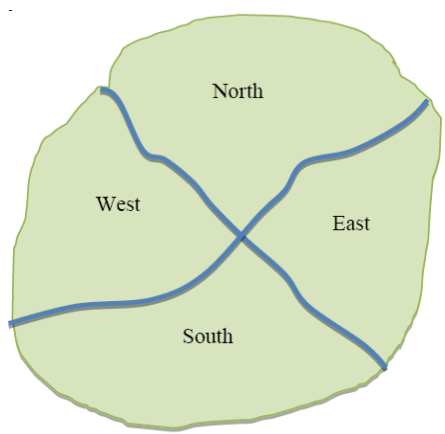

Fig. 4. Area sectors.

\section{2) Step Two}

All inward sections of the code have the same form of NLL. To satisfy the aim of direction, the first character in the inward section (xxx Nxx) can be classified according to the main four directions.

Northern Numbers: Numbers 1 and 2 represent the places that are located in the North part of the city or town.

Eastern Numbers: Numbers 3 and 4 represent the places that are located in the East part of the city or town.

Southern Numbers: Numbers 5 and 6 represent the places that are located in the South part of the city or town.

Western Numbers: Numbers 7 and 8 represent the places that are located in the West part of the city or town.

The placing of the direction indicators are illustrated in Fig. 5. Furthermore, the second and third inward characters LL are one of the 20 chosen alphabetical letters that represent the specific street.

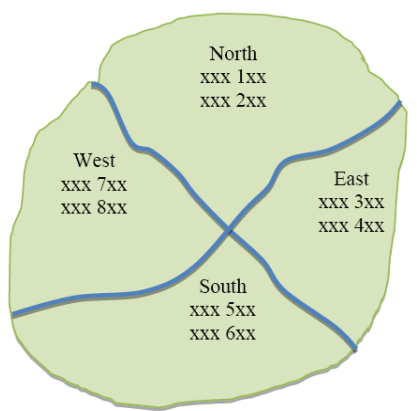

Fig. 5. Select characters for each sector.

\section{3) Step Three}

To satisfy the aim of the distance from the city centre the outward section of the postcode is used. The first, or the first and the second outward characters of the chosen postcode represent an identifying character of a city, such as A representing the city of Arbil in Iraq. The numbers of the outward section can be setup to show the distance of the point from the city centre as illustrated in Fig. 6.

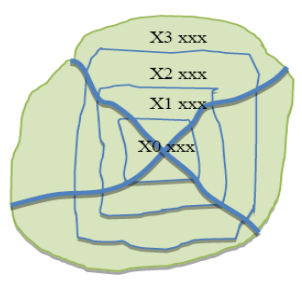

(a)

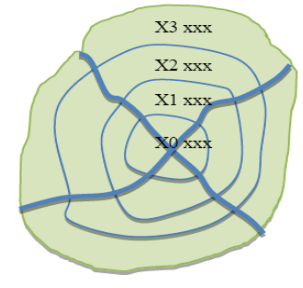

(b)
Fig. 6. Distance zones.

As shown in Fig. 6a, in cities and towns with straight streets, the divisions can be done as nested squares and in cities with circular streets, the divisions will be in nested circles as shown in Fig. 6b.

\section{4) Step Four}

At the start of the project of postcode system design for any given area, the designer should decide either to divide the area into 100 zones using the outward formats LNN, LLNN or to divide the area to 10 zones LNL, LLNL. The last character $\mathrm{L}$ at the end of outward form splits the zones up to 20 parts by using the chosen 20 alphabet characters. Fig. 7 , 
shows how zone 1 divided into 20 parts. For example the first part is X1A XXX then X1B XXX and so on.

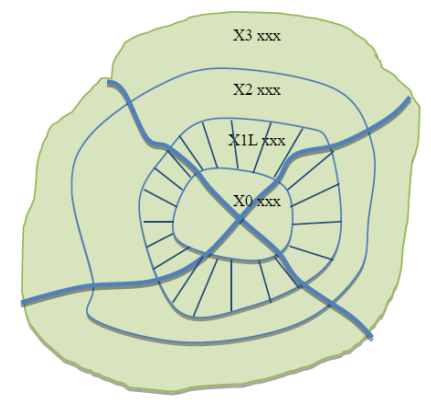

Fig. 7. Zone division.

\section{B. Analysing the Method}

The proposed postcode system method will be a combination of letters and digits and will have a limited length to represent an address. Let us assume a postcode with two characters. By using two numeric characters (from 0 to 9 ), 100 codes can be produced. The code generation can be calculated by $10^{2}=100$. While, using two alpha characters can generate 676 codes $26^{2}=676$.

As can be seen, by applying the proposed method, for any outward format we can provide up to 3,200 inward formats in the four main sections. The method provides 300 outward formats as a maximum limit sectors for any city symbol. As such, 960,000 different codes can be produced for any city or town.

Now each area (city or town) has four sections North, East, South and West. Furthermore, each area has up to 100 zones. Finally, each zone consists of four sectors due to four directions. In this research, the new postcode format can addressed up to 800 roads in each sector.

The use of alpha characters provides a greater range of postal codes and at the same time they can give a sense of location by using city or town identifying characters, such as the first letter of the location name. For example in the UK postcode system, Huddersfield is referenced by HD and Leeds by LS. An alphanumeric format is more mnemonic than that of a numeric code. In the US Zip code system, the number 1 in the first digit represents the states of Delaware,
New York or Pennsylvania [1], which does not provide a sense of location for the uninitiated.

The proposed postcode system is similar to the UK postcode, which has two parts separated by a space. However, the proposed method gives the sense of distance and direction which, is not evident in the UK postcode.

\section{Applying the Proposed Method}

To test the postcode system we used the city of Arbil in Iraq. Arbil is a good example which geographically is circular in nature with several ring roads that have been built around the city centre over several hundred years of expansion and development. Therefore, the city is divided into several circular zones that surround the city centre and each zone moving out from the centre is symbolised from 1 to $\mathrm{n}$ zones according to the distance from the centre respectively. Each zone is bordered by the aforementioned ring roads. Arbil city has a citadel at its centre which, is symbolised by the number zero in the outward section of the postcode. As such, A0 represents the Arbil citadel postcode, A1 is Arbil zone one postcode out to the first ring road and so on.

The main idea of a postcode system for Arbil is to use the circular layout as an existing resource to implement the system. Arbil, as many other cities, has several main roads to its neighboring cities. Four main roads have been selected to partition the city in to four sections: North, South, East and West. The four roads selected are Pirmam road in the North West, Malafandy road in the North East, Maxmur Road in the South East and Airport road in the South West. These roads are ideal for segregating the city in to the required directional indicators (North, South, East and West) as well as being well-known by the Arbil population. At the same time the roads continue to the centre of the city. Furthermore, five existing main ring roads are selected to divide the city into five zones. Finally, each zone consists of four directional sectors. However, the citadel of Arbil is located in the centre of the city (zone 0) and no division is applied due to the limited size of its area [10].

As shown in Fig. 8, the Google Maps API is used to visually represent the design for the postal areas. The city is divided into sixteen sectors with the citadel in the centre of the city [11].

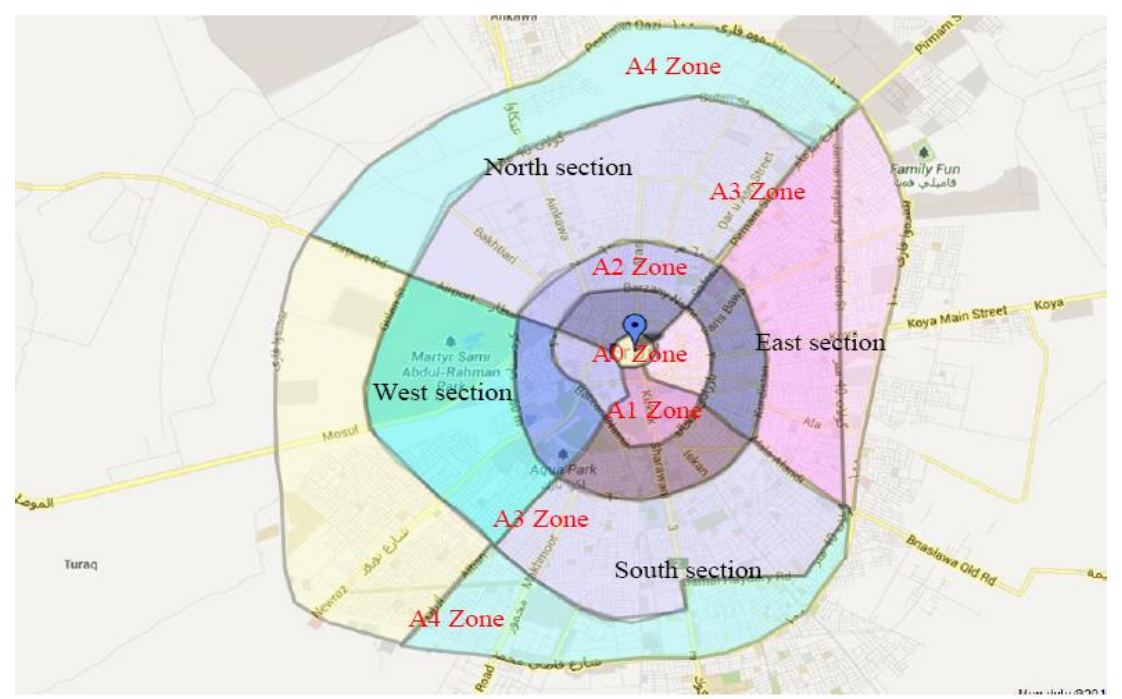

Fig. 8. Arbil sectors and zones (the original image from [12]). 


\section{The Summary of the Design}

To summarise, as a result of cities developing and expanding, the service systems for those cities also need to improve. The postcode is one of those important systems that need to develop and adapt to the growing population and the different styles and layouts of the cities and towns. In this paper, a new intelligent postcode system has been explained to give a perception of the approximate position of a specific point from the centre of a city. This intelligent system divides the city in to a number of sectors in each direction and has its own direction and zone number to shows its position. Finally, Arbil city in Iraq was chosen to apply this new postcode format as it does not yet have a postcode addressing system. This city is characterised by the circular layout of roads and areas.

\section{FUTURE WORKS}

Implementing the postcode system based on the city layout of Arbil.

Studying the working practices of service directorates, offices and companies (such as in the sectors of Education, Health and Marketing) in the use of the proposed postcode system

Developing a location based, point-to-point, navigation service based on the proposed postcode system.

\section{REFERENCES}

[1] Zip Postal Code. (2008). [Online]. Available: http://www.zippostalcodes.com/postcodes/ca/canadian-postal-codes-f ormat/.
[2] Royal Mail. (Mar 9 $\left.9^{\text {th }}, 2014\right)$. [Online]. Available: http://www.royalmail.com/.

[3] R. F. J. Anson, B. A. Khan, A. MacRae, L. Piotrowski, P. Piotrowski, E. Tomaszewski, and D. Vreuls, "Addressing and postcode manual," Switzerland: Universal Postal Union, vol. 145, 2009, Berne.

[4] J. Raper, D. Rhind, and J. Shepherd, "Postcodes: The new geography," Longman Scientific and Technical, 1992.

[5] T. H. Grubesic, "Zip codes and spatial analysis: Problems and prospects," Socio-Economic Planning Sciences, vol. 42, no. 2, pp. 129-149, 2008.

[6] United States Postal Service. [Online]. Available: http://www.unitedstateszipcodes.org/.

[7] Canada Post Corporation. (2014). Public works and government services Canada. [Online]. Available: http://www.canadapost.ca/tools/pg/manual/PGaddress-e.asp].

[8] P. Longley, Geographic Information Systems and Science, John Wiley \& Sons, 2005.

[9] G. R. Rhind, Global Sourcebook of Address Data Management: A Guide to Address Formats and Data in 194 Countries, Gower Publishing, Ltd. 1998.

[10] S. McGahey, "Tourism development in Iraq: the need for support from international academia," International Journal of Tourism Research, vol. 8, no. 3, pp. 235-239, 2006.

[11] A. Sinani, Learning Bing Maps API, Packt Publishing, 2013.

[12] Arbil Map. (2014). [Online]. Available: https://maps.google.co.uk/maps.

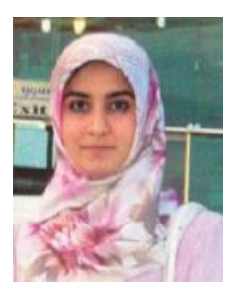

Sara R. Muhamad Amin is a PhD candidate in the School of Computing and Engineering at the University of Huddersfield, UK. She was born in Arbil, Iraq in 1983. She has awarded undergraduate certificate in computer science at Duhok University, Iraq, 2004 and then master degree in general computing at Koya University, Iraq, 2006. Her research focusing on proposing and developing design strategy of addressing, postcode system modeling, mapping and navigation system. She worked as a lecturer from 2007 to 2009 in School of Computing and Engineering of Koya University, Iraq Moreover, she taught from 2010 to 2012 in IT Department of Technical College, Arbil, Iraq. 